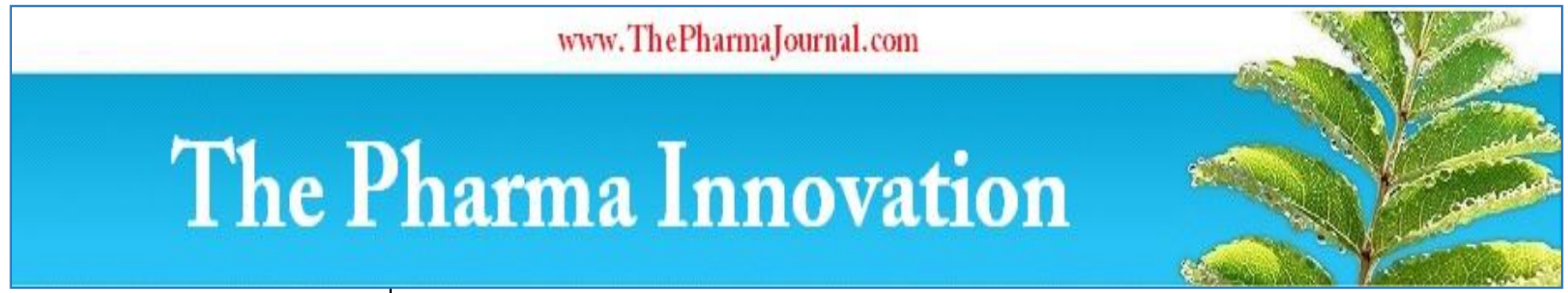

ISSN (E): 2277 - 7695

ISSN (P): 2349-8242

NAAS Rating: 5.23

TPI 2021; SP-10(4): 282-287

(C) $2021 \mathrm{TPI}$

www.thepharmajournal.com

Received: 06-02-2021

Accepted: 21-03-2021

Jagjeet Singh

Ex-MTech Scholar,

Department of Agricultural \&

Food Engineering, Indian

Institute of Technology (IIT),

Kharagpur, West Bengal, India

Abhishek Kumar

PhD Research Scholar, Indian

Agricultural Research Institute,

Pusa, New Delhi, India

Laxman Singh

Ex-BTech Student, Chaudhary

Charan Singh Haryana

Agricultural University, Hisar,

Haryana, India
Corresponding Author:

Jagjeet Singh

Ex-MTech Scholar,

Department of Agricultural \&

Food Engineering, Indian

Institute of Technology (IIT),

Kharagpur, West Bengal, India

\section{Design, development and evaluation of transplanting mechanism of single row prototype for rice seedlings}

\author{
Jagjeet Singh, Abhishek Kumar and Laxman Singh
}

DOI: https://doi.org/10.22271/tpi.2021.v10.i4Se.6069

\section{Abstract}

A transplanting mechanism is a key component in the rice transplanter as it plays a significant role in the performance of the rice transplanter. However, it affects the picking of the seedlings, planting depth, seedling damage and number of seedling per hill. Furthermore, it influences productivity and efficiency of the machine. The aim of the study described basic concept regarding design and development of four bar transplanting mechanism for rice transplanter and its evaluation. Therefore, a new transplanting mechanism for single row rice transplanter was developed and tested in laboratory as well as in field conditions. In the both conditions, five performance parameters were estimated to estimate its accuracy, of the developed mechanism such as planting depth, number of seedlings per hill, hill to hill spacing, seedling length and visible damage. The average planting depth was varied from $5.53 \mathrm{~cm}$ to $4.88 \mathrm{~cm}$ in laboratory and field conditions, respectively. However, the numbers of seedlings were found to be around 3 in both conditions. The hill to hill spacing and visible damage were also noticed within the acceptable limits for both conditions. It was concluded that prototype showed satisfactorily working ability in both conditions.

Keywords: Rice transplanter, single row transplanter, rice seedlings, four bar mechanism, hill to hill spacing, visible damage, planting depth, profile curve

\section{Introduction}

Transplanting process is adopted for the various crops across the world. It is achieved through manual operation and numerous machines have been developed for most of the crops in the world. In case for paddy crop, both manual as well as mechanical method is adopted for the transplanting of the paddy seedlings. The manual transplanting of the paddy is a labour intensive, time consuming and tedious operation. It takes from 300 to 350 man-hours per hectare and contributes around 25 percent of the total labour requirement for the production of paddy crop as reported by (Goel, 2008) ${ }^{[7]}$. Due to the shortage of the labours during the transplanting season of the paddy seedlings, leads to decrease in the production of the paddy crop.

Therefore, there is necessity for mechanization in this field, which will ensure the timely sowing of the crop. Many machines are successfully working in Japan, Korea and other parts of the world, but it could not be accepted in India due to economic constraints and cultural practices of the country. The performance of the rice transplanter highly depends on four bar transplanting mechanism, because picking and leaving of the seedlings are governed by the effective working of the transplanting mechanism. The productivity of the paddy crop is greatly affected by the number of seedlings per hill, hill to hill spacing, depth of planting, angle of transplanted seedlings, and damage percentage of seedlings as reported by (Alam

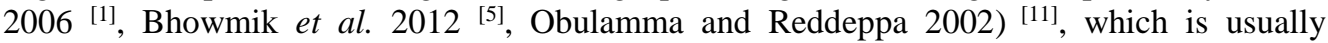
controlled by the performance of the transplanting mechanism of the transplanter. However, (Alam, et al. 2012) ${ }^{[2]}$ recommended that plant to plant spacing and number of seedlings per hill should be maintained in the range of $15 \mathrm{~cm}$ to $17 \mathrm{~cm}$ and 2 to 3 seedlings for attaining good productivity of the paddy crop, respectively, which highly depends on the effectiveness of the transplanting mechanism. Therefore, in this study, major stress was given on the design and development of four bar transplanting mechanism for single row prototype. This study also described the basic concept regarding the above mechanism, which would open the scope for the development of cheap, effective and efficient rice transplanter in the country so that it might be economically feasible for Indian farmers. 


\section{Materials and methods}

The current research work was carried out at the Department of Agricultural \& Food Engineering at Indian Institute of Technology (IIT), Kharagpur (West Bengal), India. In this study, a transplanting mechanism for single row rice transplanter prototype was designed on the basis of graphical method. Following researches have been conducted to design, develop and analyse the transplanting mechanism for the rice transplanter (Garg \& Sharma, $1984^{[6]}$; Angeles \& Bernier ${ }^{[3]}$,

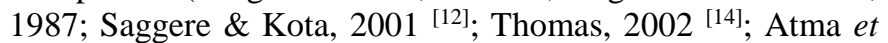

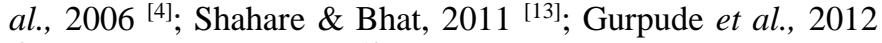
${ }^{[8]}$; Kamble et al., 2014) ${ }^{[10]}$ using different approaches. In this study, graphical method was adopted for the design of the prototype.

\subsection{Profile curve for transplanting mechanism}

The selection of the profile curve is very significant component in the design of the four-bar mechanism of rice transplanter since, it indicates the path travelled by the coupler extension of the four-bar mechanism. It determines the quality of picking and releasing of the seedlings from the seedling tray. For the selection of profile curve, graphical method was adopted. A profile curve was selected from the bunch of ten thousand profile curve for the four-bar mechanism drawn (Hartenberg and Denavit, 1964) ${ }^{[9]}$. The curve should be selected on the basis of sharpest point, which will play a role for the seedling picking point from the seedling tray. The selected curve is shown in Figure 1 and then measurement of each link was done using a measuring scale, such as PQ, PS, SR, QR and ST. The length of each link was increased by $1.5 \mathrm{~cm}$, for the attachment of all links during the fabrication of the desired four bar mechanism of the laboratory set up. The specifications of the links is given in table 1.

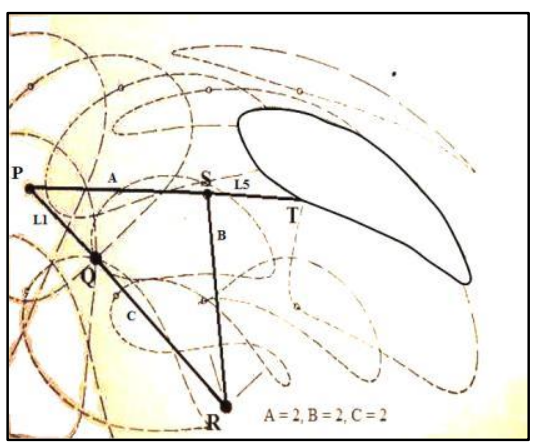

Fig 1: Selected profile curve for the prototype

\subsection{Determination of thickness of the four bar linkage}

The thickness of each link was determined by taking into the account of weight. Increase in thickness of the link would lead to increase in weight, of the overall system. The increased weight of the link leads to increase the gravity force and affects the performance of the picking and releasing efficiency of the coupler extension. If the thickness of the link will be too less, then chances of bending might increase. Therefore, there was a need of an optimum point between these two i.e. thickness neither too high nor too low. In this research, thickness of the linkage was taken as $6 \mathrm{~mm}$ to avoid unnecessary increased cost of the material as well as to avoid unnecessary increase in weight of the system.

\subsection{Determination of inclination angle of fixed link}

The inclination angle of the link means the angle of the fixed link, so that it could pick the seedling from the seedling tray and release it into the soil at a desired depth. Using the profile curve, measurement of the links was done using a measuring scale. The four links of mild steel were cut with the same length as determined and is shown in table 1. The hole (6 $\mathrm{mm}$ ) was drilled in each link and joined together with the help of nuts and bolts. The washers were used for getting the free movement and fixing of all the links. The fixed link (RQ in Figure 1) was set at certain angle and it rotated the whole mechanism to produce the profile curve. This procedure was repeated for the number of times until the transplanting point became perpendicular to the ground surface or till it attained the lowest point in the soil. In the experiments, inclination angle for the fixed link was obtained as $60^{\circ}$.

Table 1: Dimensions of the links of the transplanting mechanism

\begin{tabular}{|c|c|c|c|}
\hline Sr. No. & Links & Symbols & Dimensions (cm) \\
\hline 1 & Crank & $\mathrm{L}_{1}(\mathrm{PQ})$ & 16.5 \\
\hline 2 & Coupler & $\mathrm{A}(\mathrm{PS})$ & 30.0 \\
\hline 3 & Follower & $\mathrm{B}(\mathrm{SR})$ & 30.0 \\
\hline 4 & Fixed & $\mathrm{C}(\mathrm{RQ})$ & 30.0 \\
\hline 5 & Coupler extension & $\mathrm{L}_{5}(\mathrm{ST})$ & 13.7 \\
\hline
\end{tabular}

\subsection{Verification of the selected profile curve}

For verification of the selected curve, the transplanting finger was attached at the extension coupler point and pencil was inserted in the finger. The path was traced using the pencil to be inserted in the transplanting finger and then, compared between the selected curve and obtained curve through the fabricated mechanism (Figure 2) to verify the accuracy of the mechanism.

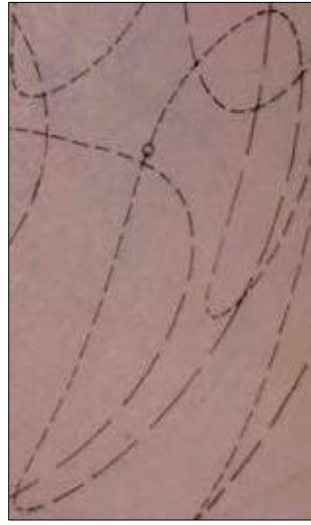

(a)

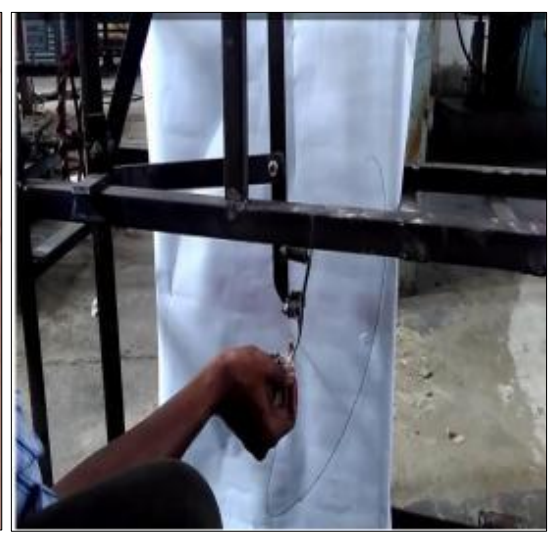

(b)

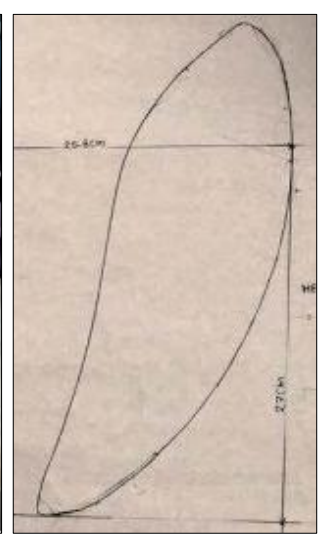

(c)

Fig 2: (a) Selected profile curve (b) tracing of curve and (c) obtained curve by the tracing procedure 


\subsection{Determination of dimensions of frame for the prototype}

After determination of the inclination angle of the fixed link, the fixed link was fixed at an angle of $60^{\circ}$ and rotation of the handle was done to revolve the mechanism for tracing the path (Figure $2 \mathrm{~b}$ ). The height of the frame was decided by measuring the height of the obtained curve (Figure $2 \mathrm{c}$ ) by considering the lowest point of the curve as planting point of the seedling. The horizontal distance of the frame was measured by a measuring scale after extending the farthest point of the extension coupler in the horizontal direction. After estimation of the dimensions of the frame such as height, length and width, the model was developed in the Solid works software. The top and side view of the mechanism is shown (Figure 3 a \& b) below along with all dimensions in $\mathrm{mm}$.

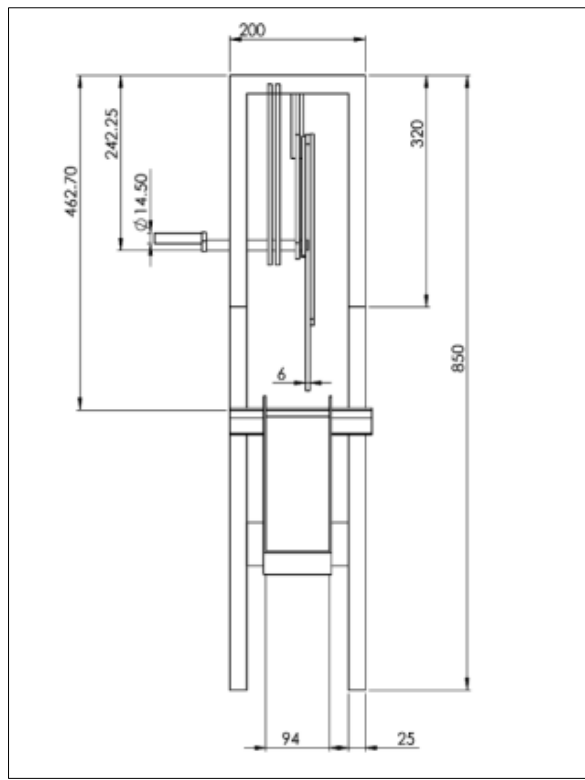

(a)

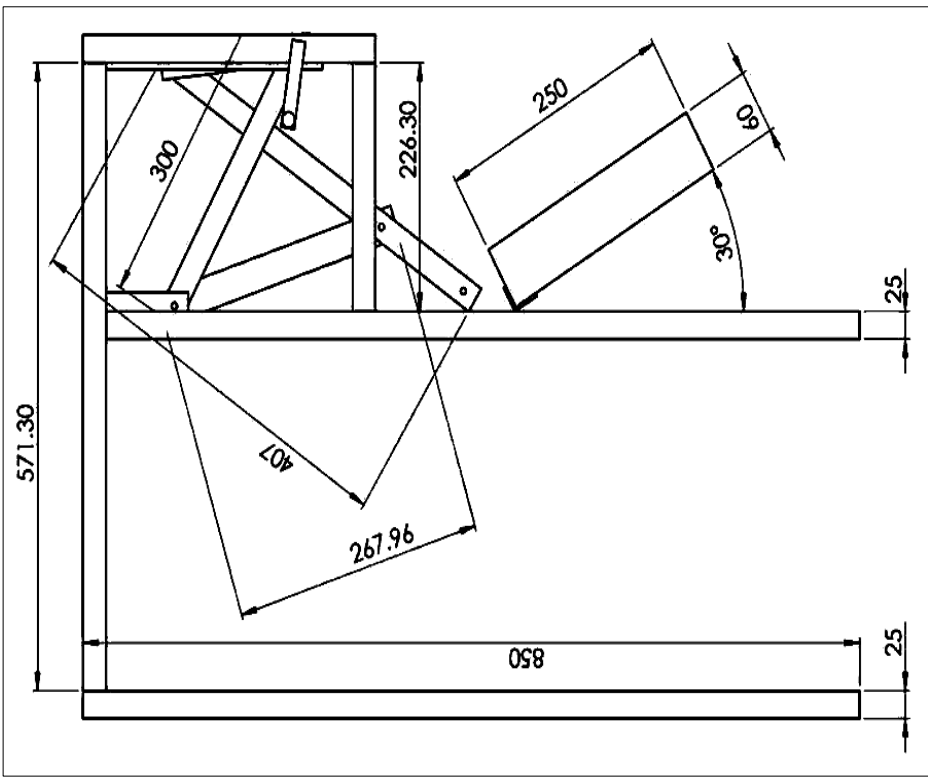

(b)

Fig 3: Dimensions of the transplanting mechanism including (a) top view and (b) side view

\subsection{Design and fabrication of float for the prototype}

Float was designed on account of number of rows and row to row spacing to be incorporated in the rice transplanter. Mild steel sheet of thickness $3 \mathrm{~mm}$ was used to fabricate the float. The front portion of the float was inclined at nearly $24^{0}$ with the horizontal in order to avoid the accumulation of the muddy soil in front of it while rest portion was kept horizontal and made of a slot size of (Width $\times$ Length: $8 \mathrm{~cm} \times 21 \mathrm{~cm}$ ) to release water as shown in Figure 4.

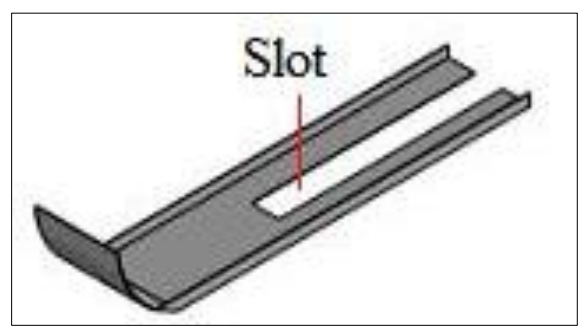

Fig 4: Float of the prototype

\subsection{Design and fabrication of seedling tray}

The seedling tray was designed in Solid works software for transplating mechanism and was tilted at nearly $45^{\circ}$ with the horizontal (Figure 5). Mild steel was used to fabricate the tray. The seedlings were picked by the transplanting finger from a slot which was provided in the frame ange bar. The slot size was (Length $\times$ Width: $1.5 \mathrm{~cm} \times 1 \mathrm{~cm}$ ) and one end of the tray was mounted on this bar and the tray carried the seedlings. It was supported at one end on the angle bar and other end, on the supports. Initially, the lateral movement of the seedling tray was done manually in laboratory conditions.

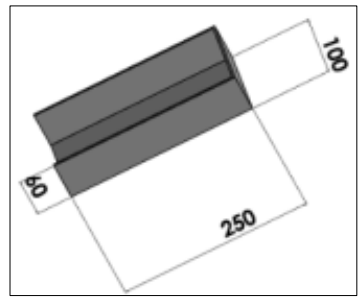

Fig 5: Dimension of seedling tray

\subsection{Design of handle to carry the unit}

The dimensions of the unit carrying handle was decided on the basis of the $5^{\text {th }}$ percentile of the population, so that most of the people can operate it. The top view of the carrying handle is shown (Figure 6), all dimension in $\mathrm{mm}$. The length of the handle plays a significant role in the reduction of effort and man tiredness. Therefore, design of the handle is necessary to increase the efficiency of the worker and as a result, worker can work for longer durations.

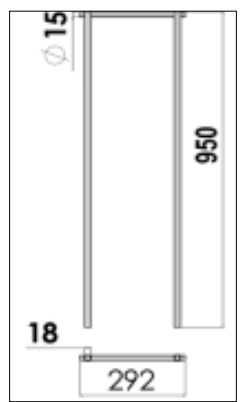

Fig 6: Dimension of handle for carrying the unit 
2.9 Fabrication of prototype single row rice transplanter After estimation of length of the four links and dimensions of the frame, the prototype was fabricated at the workshop of Agricultural \& Food Engineering at Indian Institute of Technology (IIT), Kharagpur. The mild steel material was chosen on the basis of availability of the material for construction of these links and frame (Figure 7). The transplanting mechanism consisted of the four-bar links, electric DC motor, seedling tray and fork fixed type finger. The fork fixed type finger was fabricated with galvanized iron and fixed in the coupler extension. The transplanting finger was made up of galvanized iron material and provided rectangular shaped groove on basis of its penetration into the seedling tray.

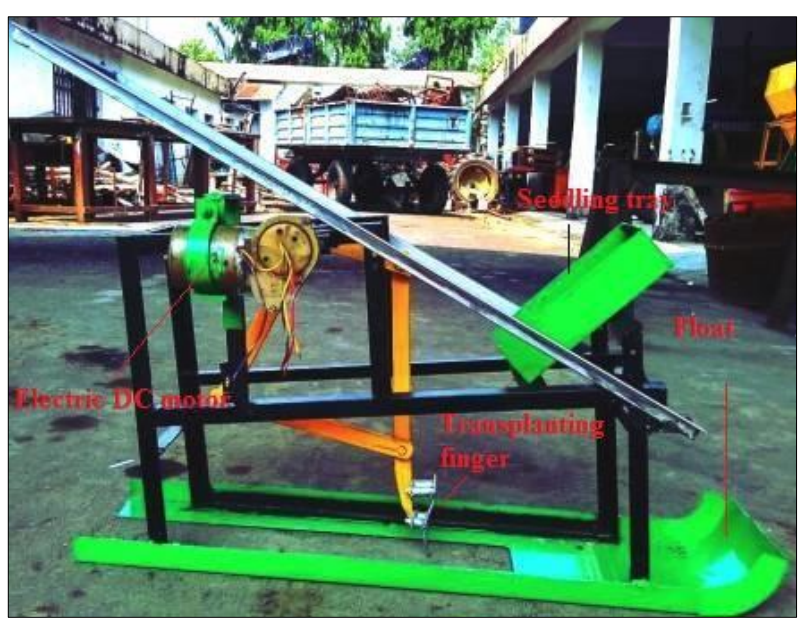

Fig 7: Prototype of single row rice transplanter

2.10 Performance evaluation of the prototype in laboratory and field conditions

The experiments were performed with developed prototype in the laboratory and mechanism was operated manually (Figure
8). The prototype was providing satisfactory performance in the laboratory conditions. However, this prototype was tested using the DC electric motor (17 Watts) in the field conditions.
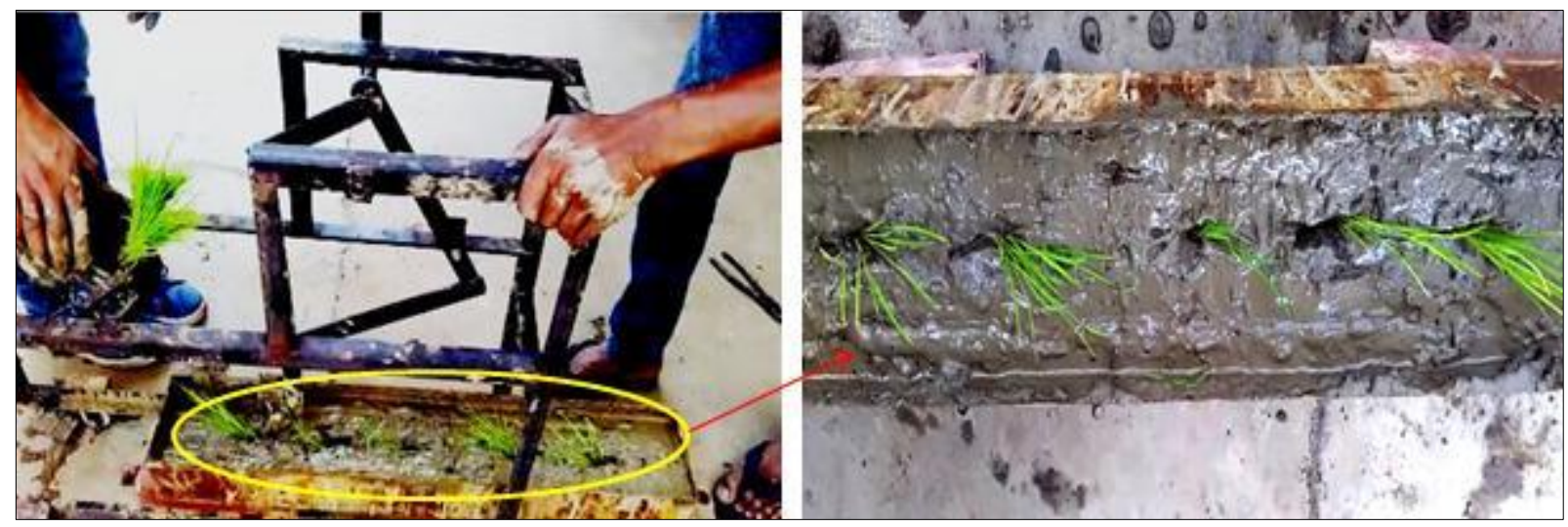

Fig 8: Testing of prototype in laboratory conditions

\section{Results \& discussion}

\subsection{Performance in laboratory conditions}

The manually operated prototype single row rice transplanter was tested in laboratory conditions and estimated different performance parameters such as depth of planting, hill to hill spacing, number of seedlings per hill and visible damage; mean and standard deviation of each parameters are shown (Table 2). The results revealed that all determined performance parameters recorded, were within acceptable limits.

Table 2: Measurement of different performance parameters: planting depth, seedlings length, hill to hill spacing, number of seedling/hill and visible damage in lab conditions.

\begin{tabular}{|c|c|c|c|c|c|}
\hline Sr. No. & Planting depth $(\mathbf{c m})$ & Seedling length $(\mathbf{c m})$ & Hill to hill spacing $(\mathbf{c m})$ & Number of seedlings/hill & Visible damage \\
\hline 1 & 5.4 & 17.0 & 13.5 & 5 & 0 \\
\hline 2 & 6.1 & 19.2 & 15.0 & 3 & 0 \\
\hline 3 & 5.5 & 15.4 & 16.5 & 2 & 0 \\
\hline 4 & 5.3 & 16.1 & 14.5 & 4 & 0 \\
\hline 5 & 4.5 & 17.0 & 16.0 & 5 & 1 \\
\hline 6 & 6.0 & 17.7 & 15.5 & 2 & 0 \\
\hline 7 & 6.2 & 14.2 & 15.0 & 1 & 0 \\
\hline 8 & 4.3 & 19.2 & 13.5 & 3 & 1 \\
\hline 9 & 6.0 & 17.3 & 14.0 & 2 & 0 \\
\hline
\end{tabular}




\begin{tabular}{|c|c|c|c|c|c|}
\hline 10 & 6.4 & 19.5 & 12.0 & 3 & 0 \\
\hline 11 & 5.1 & 15.0 & 13.5 & 2 & 0 \\
\hline Mean & 5.53 & 17.05 & 14.45 & 2.91 & 0.18 \\
\hline S.D. & 0.66 & 1.70 & 1.25 & 0.35 & \\
\hline
\end{tabular}

\subsection{Performance in field conditions}

The experiments were carried out using developed prototype of the single row rice transplanter in the puddled field size $(2$ $\mathrm{m} \times 2 \mathrm{~m})$. The five performance parameters were estimated viz: planting depth, hill to hill spacing, number of seedlings per hill and visible damage; mean and standard deviation
(Table 3). The result showed that the planting depth ranged from 4.6 to $6.12 \mathrm{~cm}$ with mean $\pm \mathrm{SD}(4.88 \pm 0.76 \mathrm{~cm})$ which made an agreement with (Alam et al. 2012) ${ }^{[2]}$. On an average, number of seedlings per hill was noticed to be around 3 which is in the acceptable range.

Table 3: Measurement of various performance parameters: depth of planting, seedlings length, hill to hill spacing, number of seedling/hill and visible damage in field conditions.

\begin{tabular}{|c|c|c|c|c|c|}
\hline Sr. No. & Planting depth (cm) & Hill to hill spacing (cm) & Seedlings length $(\mathrm{cm})$ & Damaged seedlings & No. of seedlings \\
\hline 1 & 5.5 & 18.7 & 19.0 & 2 & 5 \\
\hline 2 & 5.4 & 17.5 & 18.5 & 0 & 4 \\
\hline 3 & 4.7 & 18.5 & 18.8 & 1 & 3 \\
\hline 4 & Missing & Missing & Missing & Missing & Missing \\
\hline 5 & 5.0 & 18.0 & 17.5 & 0 & 4 \\
\hline 6 & 5.8 & 17.6 & 19.5 & 0 & 4 \\
\hline 7 & 6.0 & 19.0 & 18.9 & 1 & 5 \\
\hline 8 & 5.2 & 20.2 & 19.0 & 0 & 3 \\
\hline 9 & 5.4 & 19.0 & 18.7 & 1 & 2 \\
\hline 10 & 5.5 & 20.2 & 16.5 & 0 & 3 \\
\hline 11 & 5.0 & 17.0 & 17.0 & 3 & 6 \\
\hline 12 & 5.4 & 15.9 & 18.5 & 0 & 2 \\
\hline 13 & 6.1 & 18.0 & 19.5 & 0 & 1 \\
\hline 14 & 5.0 & 21.0 & 17.3 & 1 & 3 \\
\hline 15 & 5.8 & 16.3 & 17.0 & 1 & 4 \\
\hline 16 & 5.0 & 17.6 & 18.5 & 2 & 4 \\
\hline 17 & 5.0 & 16.4 & 18.2 & 0 & 5 \\
\hline 18 & 5.1 & 16.8 & 17.6 & 0 & 1 \\
\hline 19 & 6.5 & 17.3 & 16.9 & 0 & 3 \\
\hline 20 & 5.0 & 17.0 & 16.3 & 3 & 6 \\
\hline 21 & 5.6 & 15.6 & 17.0 & 0 & 4 \\
\hline 22 & 5.2 & 21.0 & 18.3 & 0 & 2 \\
\hline 23 & 5.0 & 16.4 & 17.0 & 1 & 6 \\
\hline 24 & 4.9 & 23.0 & 17.8 & 0 & 3 \\
\hline 25 & 5.8 & 18.8 & 20.3 & 0 & 3 \\
\hline Mean & 5.37 & 18.20 & 18.07 & 0.67 & 3.58 \\
\hline S.D. & 0.44 & 1.80 & 1.04 & 0.94 & 1.41 \\
\hline
\end{tabular}

\section{Conclusions}

This study described the development of a prototype of the transplanting mechanism for single row rice transplanter. However, it was tested in both laboratory and field conditions. The transplanting mechanism was operated manually in the laboratory, while by an electric DC motor in the field conditions. From the data observations, following conclusions were drawn. The transplanting mechanism performed well in the laboratory conditions by providing the acceptable value of the following parameters such as planting depth, number of seedlings per hill, hill to hill spacing and visible damage. The number of seedlings per hill was found to be around 3 in the laboratory as well as in the field conditions, which is within acceptable limits. The average depth of planting was observed to be $5.53 \mathrm{~cm}$ and $4.88 \mathrm{~cm}$ in laboratory and field conditions, respectively. The average hill to hill spacing was recorded as $17.05 \mathrm{~cm}$ and $16.39 \mathrm{~cm}$ in laboratory and field conditions, respectively. The visible damage was also noticed to be within acceptable limits for both the conditions, but number on missings in the field were more in comparison to the laboratory conditions.

\section{Acknowledgement}

I, Jagjeet Singh thank my father Shri Leela Singh and my beloved mother Smt. Sita Devi for all the blessings they have showered on me throughout the life.

\section{References}

1. Alam F. Effect of spacing, number of seedlings hill-1 and fertilizer management on the performance of Boro rice cv. BRRI dhan 29. M. S. Thesis, Dept. Agron., Bangladesh Agril. Univ., Mymensingh. 2006, 24-27.

2. Alam MS, Baki MA, Sultana MS, Ali KJ, Islam MS. Effect of variety, spacing and number of seedlings per hill on the yield potentials of transplant aman rice. International Journal of Agronomy and Agricultural Research 2012;2(12):10-15.

3. Angeles J, Bernier A. A general method of four-bar linkage mobility analysis. Journal of mechanisms, transmissions, and automation in design 1987;109(2), 197-203.

4. Atma D, Pitoyo Budiman, Joko Rosmeika, Sulistiadji Koes, Sulistiadji. Design and development of manual rice transplanters. J Agric. Engg. Res 2006;43:350-357. 
5. Bhowmik SK, Sarkar MAR, Zaman F. Effect of spacing and number of seedlings per hill on the performance of aus rice cv. NERICA 1 under dry direct seeded rice (DDSR) system of cultivation. J Bangladesh Agril. Univ 2012;10(2):191-195.

6. Garg IK, Sharma VK. Design, development and evaluation of PAU riding type engine operated paddy transplanter using mat type seedlings. Proc. ISAE. SJC 1984;1(2):7-63.

7. Goel AK, Behera D, Swain S. Effect of sedimentation period on performance of rice transplanter. Agricultural Engineering International: CIGR Journal. Manuscript PM 07034. 2008, X.

8. Gurpude RR, Ashkhedkar RD, Handa CC, Choudhary S.K. Design, synthesis and simulation of four bar mechanism for wheels for climbing. International Journal of Computer Technology and Electronics Engineering (IJCTEE) 2012;2(2):218-220.

9. Hartenberg R, Danavit J. Kinematic synthesis of linkages. New York: McGraw-Hill., Language: English, ISBN-10: 0070269106, 1964, 187-188.

10. Kamble PK, Handa CC, Zode PN. Generalized methodology of synthesis of four bar mechanism. International Journal of Mechanical Engineering and Robotics Research 2014;3(1):160-165.

11. Obulamma UA, Reddeppa R. Effect of spacing and seedling number on growth and yield of hybrid rice. $\mathrm{J}$ Res. ANGRAU 2002;30(1): 76-78.

12. Saggere L, Kota S. Synthesis of planar, compliant fourbar mechanisms for compliant-segment motion generation. Journal of Mechanical Design 2001;123(4):535-541.

13. Shahare PU, Bhat MR. Development and performance evaluation of two row paddy transplanter, Internet $\mathrm{J}$ Agric. Engg 2011;4(1):103 -105.

14. Thomas EV. Development of a mechanism for transplanting rice seedlings. Mechanism and machine theory 2002;37(4):395-410. 